\title{
Pelatihan Pembuatan Pupuk Organik Cair (POC) dari Limbah Dapur bagi Ibu-Ibu Desa Paya Kecamatan Trienggadeng Kabupaten Pidie Jaya
}

\author{
Lia Handayani ${ }^{1}$ \\ Program Studi Teknologi Hasil Perikanan, Fakultas Perikanan, Universitas Abulyatama \\ liahandayani_thp@abulyatama.ac.id \\ Nurhayati ${ }^{2}$ \\ Program Studi Budidaya Perairan Fakultas Perikanan Universitas Abulyatama, \\ nurhayati_perairan@abulyatama.ac.id \\ Cut Rahmawati ${ }^{3}$ \\ Program Studi Teknik Sipil Universitas Abulyatama, cutrahmawati@abulyatama.ac.id \\ Meliyana ${ }^{4}$ \\ Program Studi Teknik Sipil Universitas Abulyatama, meliyana_sipil@abulyatama.ac.id
}

\begin{abstract}
Abstrak
Limbah merupakan permasalahan yang belum terpecahkan. Limbah yang dihasilkan manusia terdiri dari limbah organik dan an-organik. Limbah organik yang dihasilkan bersumber dari sampah dapur sisa kegiatan masak memasak, limbah dapur ini jika dibuang begitu saja dapat menimbulkan aroma yang tidak sedap, selain itu juga akan memicu pertumbuhan mikroorganisme penyebab penyakit. Limbah organik setidaknya dapat lebih termanfaatkan dibandingkan limbah anorganik yaitu dengan mengubahnya menjadi pupuk. Lokasi pengabdian berada di Desa Paya Kecamatan Trienggadeng Kabupaten Pidie Jaya, Aceh. Ibu-ibu di desa ini membuang sampah dapur mereka begitu saya di tong sampah, halaman belakang rumah atau dimana saja tanpa adanya upaya penanganan. Tujuan yang ingin dicapai dari kegiatan pelatihan pembuatan pupuk organik (POC) dari limbah organik yang dihasilkan oleh rumah tangga adalah memberikan informasi pengetahuan serta menumbuhkan kesadaran masyarakat terhadap pentingnya pengolahan limbah secara efisien, sehingga masayarakat Desa Paya Kecamatan Trienggadeng tidak sembarangan menumpuk sampah-sampah organik yang nantinya akan menimbulkan aroma tak sedap sehingga mengundang penyebaran bibit penyakit. Metode yang diterapkan dalam kegiatan ini adalah menyajikan materi kemudian melakukan praktik langsung untuk membuat POC. Kemudian dilakukan evaluasi terhadap produk yang dihasilkan dan proses yang dilaksanakan oleh peserta pelatihan. Hasil kegiatan menunjukkan Ibu-ibu Desa Paya sudah dapat membuat POC sendiri. Hal ini terlihat dari kesesuaian kualitas produk yang dihasilkan dengan target kualitas produk. Pengabdian masyarakat ini berhasil menumbuhkan kesadaran ibu-ibu Desa Paya akan pentingnya hidup sehat dan kreatif, memotivasi ibu-ibu agar tidak mendekati pestisida dan pupuk kimia dan beralih kepada pupuk organik cair (POC).
\end{abstract}

Kata Kunci: limbah organik, Pupuk Organik Cair (POC), sisa dapur 


\title{
JURNAL ABDIMAS BSI
}

Jurnal Pengabdian Kepada Masyarakat

\begin{abstract}
Waste is an unsolved problem. The waste produced by humans consists of organic and inorganic waste. Organic waste comes from kitchen leftovers from cooking activities, if this kitchen leftovers is thrown away it can cause unpleasant odor, but it will also trigger the growth of disease-causing microorganisms. Organic waste can at least be more utilized than inorganic waste by turning it into fertilizer. The location of the community service was in Paya Village, Trienggadeng, Pidie Jaya Regency, Aceh. The women in this village just thrown away their kitchen waste in trash cans, backyards or anywhere without any effort to handle it. The aim of the training of making organic fertilizer (POC) from organic waste produced by households is to provide information on knowledge and to raise public awareness of the importance of efficient waste management, so that the Paya community in Trienggadeng sub-district does not carelessly accumulate organic waste that will later cause unpleasant odors that invite the spread of germs. The method applied in this activity is to present the material and then conduct a hands-on practice to create a POC. Then made an evaluation of the products produced and the process carried out by trainees. The results of the activity shown that the Paya Village women can make their own POC. It can be seen from the suitability of the product quality produced with the product quality target. This community service has succeeded in raising awareness of Paya Village women about the importance of healthy and creative living, motivating them not to approach pesticides as well as chemical fertilizers and switch to liquid organic fertilizer (POC).
\end{abstract}

Keywords: liquid organic fertilizer, organic waste, kitchen waste

\section{Pendahuluan}

Permasalahan limbah yang dihasilkan oleh kehidupan manusia tidak pernah luput dari dampak yang muncul kemudiannya. Limbah yang dihasilkan oleh kegiatan manusia tidak hanya berupa limbah anorganik seperti plastik, namun juga ada limbah organik (Sulistyorini, 2005). Limbah organik yang dihasilkan oleh kehidupan rumah tangga bersumber dari sampah dapur sisa kegiatan masak memasak, limbah dapur ini jika dibuang begitu saja dapat menimbulkan aroma yang tidak sedap, selain itu juga akan memicu pertumbuhan mikroorganisme penyebab penyakit. Sampah menggunung dapat menyebabkan meningkatnya degradasi kebersihan lingkungan karena mengeluarkan gas metan yang menyebabkan global warming (Indriyanti, Banowati, \& Margunani, 2015).

Sampah dapur yang dihasilkan oleh kegiatan rumah tangga setiap harinya akan terjadi penumpukan, karena kegiatan memasak dilakukan setiap harinya, bahkan ada rumah tangga yang dapat memproduksi sampah dapur dengan intensitas 3 kali sehari dan akan terus menumpuk jika tidak dilakukan pengelolaan yang tepat. Salah satu cara yang dapat menyelesaikan persoalan sampah organik adalah dengan pendekatan teknologi yaitu merubahnya menjadi pupuk (Aklis \& Masyrukan, 2016).

Sasaran kegiatan ini adalah ibu-ibu Desa Paya. Ibu-ibu Desa Paya sebagian besar bermata pencaharian sebagai petani membantu usaha suami di ladang, selain 
itu ada beberapa diantara mereka melakukan bercocok tanam dengan memanfaatkan lahan pekarangan dengan menanam berbagai pohon sayur-sayuran untuk mengurangi biaya pengeluaran belanja sehari-hari. Ibu-ibu desa ini biasa membuang sampah dapur pada tempat pembuangan sampah atau membuang ke halaman belakang rumah. Sampah dibuang begitu saja tanpa adanya pemisahan antara sampah organik dan anorganik.

Berdasarkan urairan tersebut maka dilakukan pelatihan pembuatan Pupuk Organik Cair dari sampah organik (sayuran dan buah-buahan) yang dihasilkan oleh dapur masing-masing ibu-ibu Desa Paya. Hal ini untuk mengajak masyarakat meminimalisir penumpukan sampah organik. Selain itu pupuk organik cair yang dihasilkan juga dapat digunakan untuk bercocok tanam ibu-ibu skala rumah tangga seperti menaman sayuran di pekarangan sehingga dapat mengantisipasi penggunaan pestisida dan pupuk kimia. Pupuk organik cair mengandung unsur karbon dan nitrogen yang sangat penting dalam memperbaiki kesuburan tanah (Meriatna, Suryati, \& Fahri, 2018).

Dengan adanya kegiatan pelatihan ini diharapkan dapat menumbuhkan kesadaran masyarakat akan pentingnya hidup sehat dan kreatif sehingga dapat ditularkan kepada warga lain. Kreatif yang dimaksud adalah kreatif mengolah limbah menjadi bahan yang lebih bermanfaat dan bernilai ekonomis. Produksi Pupuk Organik Cair (POC) dalam skala besar akan dapat mendatangkan nilai ekonomis. Selain itu, penggunaan POC ini diharapkan dapat memotivasi masyarakat untuk hidup sehat dengan tidak mendekati pestisida dan pupuk kimia, yang kemudian beralih kepada pupuk organik cair (POC).

\section{Metode}

Metode yang diterapkan dalam kegiatan ini adalah pelatihan dan praktik langsung. Dalam pelatihan ini diberikan beberapa kegiatan yang meliputi penyajian materi, dan praktik pembuatan Pupuk Organik Cair (POC) oleh para pelaksana pengabdian kepada masyarakat yang berpengalaman dalam bidangnya. Adapun langkah yang ditempuh dalam kegiatan Pengabdian Masyarakat ini mencakup beberapa tahap berikut ini:

1. Persiapan

Pada tahap ini dilakukan koordinasi tim pelaksana terkait tempat pelaksanaan praktik dan penyajian materi. Selain itu persiapan operasional dilakukan dengan mendatangi kepala desa untuk meminta ijin ibu-ibu melakukan pelatihan/praktik pembuatan pupuk organik cair (POC) di Desa Paya. selanjutnya diperoleh data sesuai kesanggupan dan kesediaan warga dalam kepesertaan didapat peserta sebanyak 15 orang yang menyatakan sanggup sebagai peserta pelatihan. Keseluruhan peserta adalah ibu-ibu rumah tangga dan aktif dalam kegiatan PKK dan pengajian. Pelatihan dilakukan dengan membagikan konsumsi dan daftar hadir yang wajib ditanda tangani oleh peserta.

Bahan limbah dapur disiapkan oleh peserta. Bahan yang disiapkan pelaksana pengabdian kepada masyarakat berupa EM4 dan Molase. EM4 merupakan kultur campuran dari mikroorganisme yang digunakan untuk meningkatkan populasi 
mikroorganisme (Siswati, Theodorus, \& Eko S, 2009) (Ramaditya, Hardiono, \& Ali As, 2017). EM4 ini bertujuan untuk mempercepat proses pembuatan pupuk cair, menetralkan bahan organik, dan meningkatkan kualitas pupuk cair (Nur, Noor, \& Elma, 2016). Pada kegiatan ini juga digunakan molase berupa gula putih yang dijual di pasar. Molase merupakan tambahan sumber karbohidrat pada medium pertumbuhan mikroorganisme (Fifendy, Eldini, \& Irdawati, 2013).

2. Pelaksanaan pelatihan

Tahap ini merupakan tahap pelatihan pembuatan pupuk organik cair bagi ibu-ibu Desa Paya Kecamatan Trienggadeng Kabupaten Pidie jaya yang meliputi beberapa hal pelaksaan berikut:

a. Penyajian materi

Materi yang disajikan terkait pemanfaatan sampah organik dari dapur rumah tangga menjadi POC seperti proses pembuatannya, bahan-bahan yang butuhkan dan mekanisme saat proses pembuatannya. Materi disajikan dalam bentuk presentasi. Selain itu, juga disampaikan beberapa manfaat POC serta kelebihan POC dibanding pupuk kimia lainnya.

b. Praktik pembuatan Pupuk Organik Cair (POC)

Setelah mendapatkan teori, peserta akan diajak praktik langsung membuat POC dari sisa dapur yang telah dibawa masing-masing oleh peserta. Sedangkan EM4 disediakan oleh pelaksana teknis. Dalam tahap ini para peserta diajarkan tahap-tahap pembuatan POC dengan baik dan benar sehingga dapat diperoleh POC yang berkualitas. Apabila timbul permasalahan pada tahap pembuatan POC maka tim pelaksana akan memberi solusi dengan penjelasan-penjelasan yang relevan, sehingga tujuan akhir dari program dapat tercapai.

c. Penutupan

Di akhir kegiatan peserta dan Tim melakukan refleksi hasil pelatihan dan para peserta juga memberikan evaluasi akan pelatihan ini. Setelah semua kegiatan yang telah direncanakan terlaksana, ketua tim Pengabdian menutup program dan memberikan pesan kepada segenap peserta pelatihan untuk menerapkan apa yang telah didapatkan untuk memperkaya pembelajaran kreativitas dan hidup sehat tanpa pestisida dan pupuk kimia serta tidak ada lagi menimbun sampah organik di setiap rumah yang dapat berdampak munculnya bibit penyakit.

Adapun skema pembuatan POC yang dipraktekkan pada pelatihan yang dilaksanakan di Desa Paya Kecamatan Trienggadeng Kabupaten Pidie Jaya adalah sebagai berikut: 


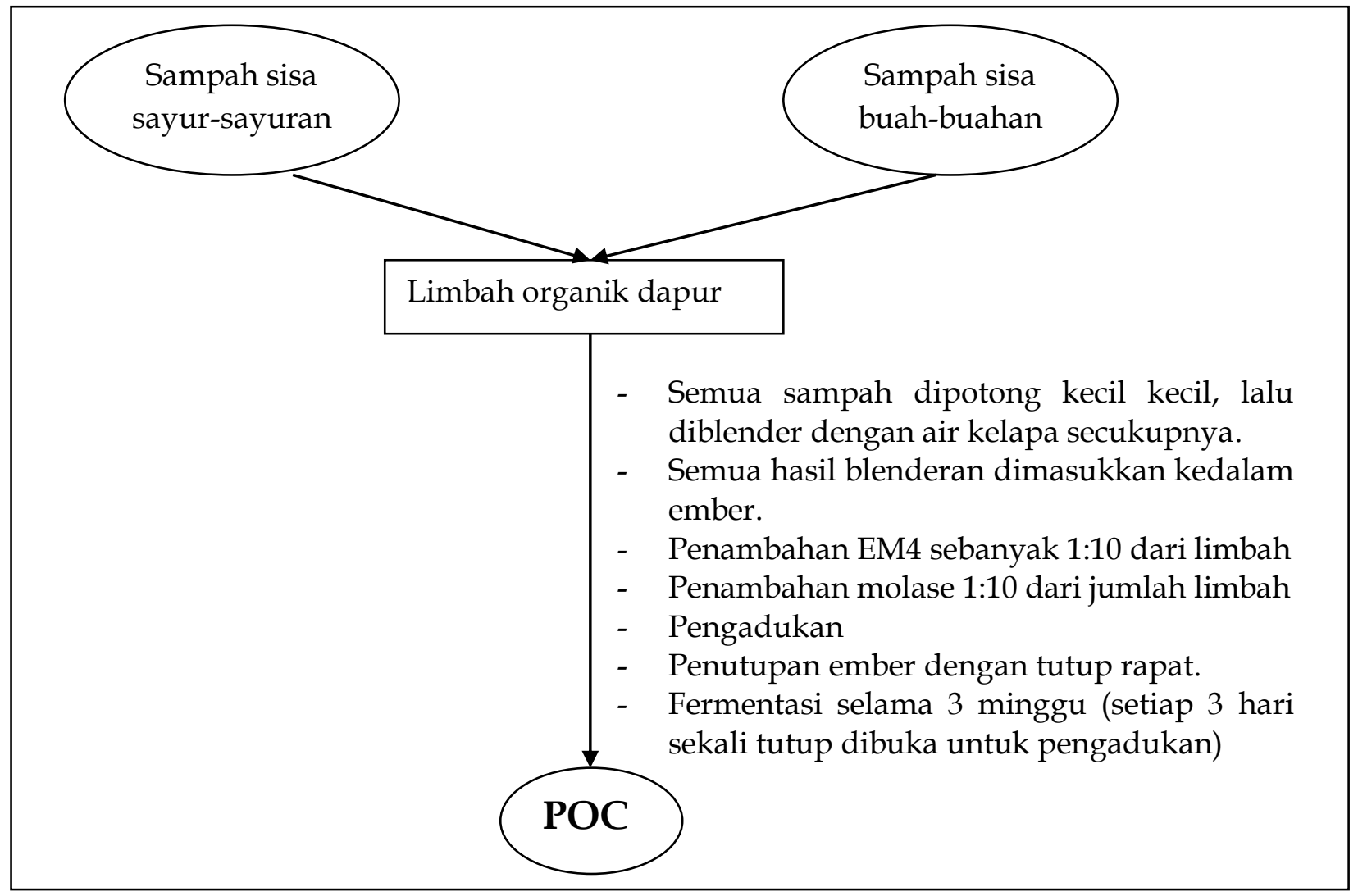

Gambar 1. Skema Proses Pembuatan Pupuk Cair Organik (POC) dari limbah dapur.

\section{Hasil dan Pembahasan}

Pelatihan keterampilan pembuatan POC dari limbah organik sisa dapur diharapkan dapat memotivasi masyarakat untuk kembali go green dengan tidak lagi menggunakan pestisida dan pupuk kimia sehingga masyarakat Desa Paya Kecamatan Trienggadeng Kabupaten Pidie Jaya kembali hidup sehat bebas zat kimia selain itu juga menumbuhkan sisi kreatif dari ibu-ibu dalam memanfaatkan limbah organik yang dihasilkan setiap harinya oleh dapur ibu ibu. Kegiatan ini dapat ditularkan kepada ibu-ibu ynag lain. Pembuatan POC meminimalisir penggunakan senyawa kimia dan dapat menambah penghasilan keluarga serta memasyarakatkan daur ulang sampah organik dapur.
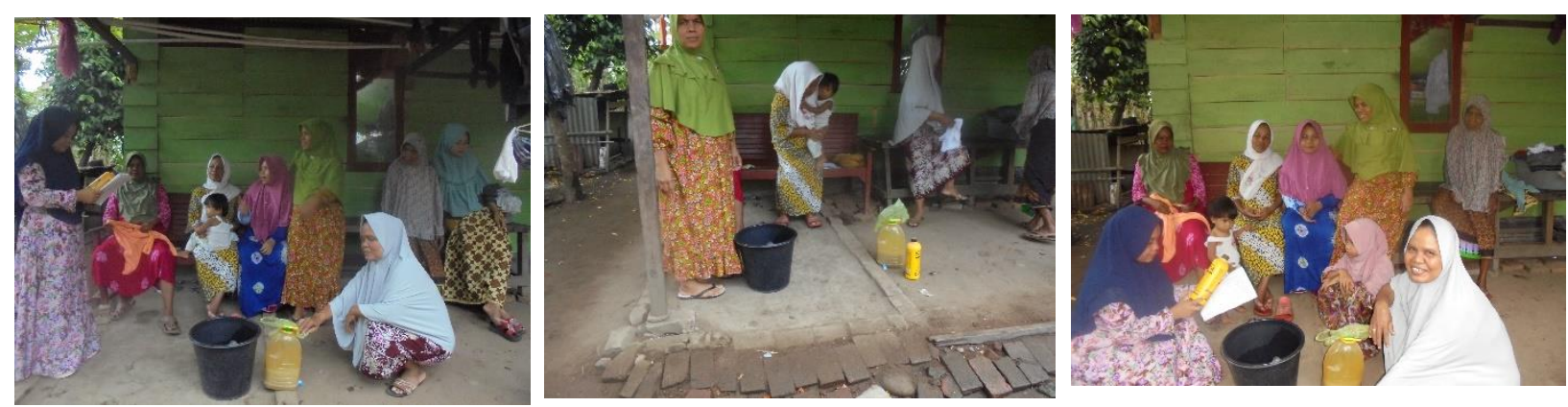

Gambar 2. Pelaksanaan kegiatan pelatihan POC bagi ibu-ibu Desa Paya 
Evaluasi kegiatan Pengabdian masyarakat ini dilakukan melalui beberapa cara, yaitu evaluasi terhadap proses dan evaluasi terhadap hasil. Evaluasi proses dapat dilihat dari keseriusan para peserta dalam mengerjakan tugas praktik pembuatan POC dan mengumpulkan sampah organik yang telah diinstruksikan beberapa hari sebelum acara pelatihan dimulai. Peserta sangat serius dalam proses pelatihan, terlihat banyak pertanyaan-pertanyaan yang disampaikan oleh peserta kepada tim pelaksana. Produk POC yang dihasilkan ibu-ibu dinilai dan hal ini menggambarkan keberhasilan materi yang telah disajikan. Pada akhir kegiatan, Tim menjaring data kebermaknaan program kepada para peserta. Mayoritas peserta pelatihan menginginkan keberlanjutan program pelatihan dengan tema-tema lainnya, karena merasa pelatihan yang telah diberikan sangat bermanfaat bagi mereka.

\section{Simpulan dan Rekomendasi}

1. Proses pembuatan POC dari bahan-bahan organik sisa dapur yang dilaksanakan pada pelatihan terdiri dari pelaksana memberikan materi berupa pengetahuan informasi-informasi mengenai POC, kegunaan, cara pembuatan serta bahanbahan pendukung dalam pembuatan POC. Informasi cara pembuatan meliputi faktor-faktor yang mempengaruhi terbentuknya POC yang sesuai baku mutu agar sesuai dengan kebutuhan tanaman.

2. Ibu-ibu Desa Paya sudah dapat membuat POC sendiri, hal ini dilihat dari kualitas produk yang dihasilkan sudah sesuai dengan materi yang diberikan.

3. Pengabdian masyarakat ini berhasil menumbuhkan kesadaran masyarakat akan pentingnya hidup sehat dan kreatif, memotivasi masyarakat agar tidak mendekati pestisida dan pupuk kimia dan beralih kepada pupuk organik cair (POC).

4. Berdasarkan evaluasi yang telah dilakukan terhadap ibu-ibu Desa Paya, perlu dilakukan pelatihan-pelatihan serupa lainnya yang dapat membangun daya kreatifitas masyarakat mengingat keikutsertaan dan antusiasme yang tinggi terhadap program yang dilaksanakan.

\section{Daftar Pustaka}

Aklis, N., \& Masyrukan, M. (2016). Penanganan Sampah Organik Dengan Bak Sampah Komposter di Dusun Susukan Kelurahan Susukan Kecamatan Susukan Kabupaten Semarang. Warta, 19(1), 74-82.

Fifendy, M., Eldini, E., \& Irdawati, I. (2013). Pengaruh Pemanfaatan Molase Terhadap Jumlah Mikroba Dan Ketebalan Nata Pada Teh Kombucha. In Prosiding Semirata FMIPA Universitas Lampung (pp. 67-72).

Indriyanti, D. R., Banowati, E., \& Margunani, M. (2015). Pengolahan Limbah Organik Sampah Pasar Menjadi Kompos. Jurnal Abdimas, 19(1), 43-48.

Meriatna, M., Suryati, S., \& Fahri, A. (2018). Pengaruh Waktu Fermentasi dan Volume Bio Aktivator EM4 (Effective Microorganisme) pada Pembuatan Pupuk Organik Cair (POC) dari Limbah Buah-Buahan. Jurnal Teknologi Kimia Unimal, 
Jurnal Pengabdian Kepada Masyarakat

$7(1), 13-29$.

Nur, T., Noor, A. R., \& Elma, M. (2016). Pembuatan Pupuk Organik Cair Dari Sampah Organik Rumah Tangga Dengan Penambahan Bioaktivator EM4 (Effective Microorganisms). Konversi, 5(2).

Ramaditya, I., Hardiono, \& Ali As, Z. (2017). Pengaruh Penambahan Bioaktivator EM-4 (Effective microorganism) dan Mol (Mikroorganisme Lokal) Nasi Basi Terhadap Waktu Terjadinya Kompos. Jurnal Kesehatan Lingkungan, 14(1), 415423.

Siswati, N. D., Theodorus, H., \& Eko S, P. W. (2009). Kajian Penambahan Effective Microorganisms (EM4) Pada Proses Dekomposisi Limbah Padat Industri Kertas. Buana Sains, 9(1), 63-68.

Sulistyorini, L. (2005). Pengolahan Sampah Dengan Cara Menjadikannya Kompos. Jurnal Kesehatan Lingkungan, 2(1), 77-84. 